\title{
COMMUNICATIVE APPROACH: CLASSROOM INTERACTION AT HIGHSCHOOL (A Case at Jiren High school, Grade 10 in Focus)
}

\author{
Aschalew Adera *Yemanebirhan Kelemwork **
}

\begin{abstract}
Even though Communicative Approach is vast in its depth and breadth, classroom interaction is an indispensable component of it. Therefore, this research work endeavored to look in to the three elements of classroom interaction (individual participation, pair, and group formation) at grade ten classes of high school. The study tries to provide strongly factual information supported by more of qualitative analysis. This is actually realized with three data collection methods: observation, questionnaire and focus group discussions. For example, FGD was facilitated among eighteen students randomly taken from eighteen sections. Finally, the study identified around seven major findings which recommendations have been made for. In fact, almost all teachers in the high school don't have the habit of organizing their students either in-group or in pair before the start of the lesson; however, some teachers go around the students at the time of discussion although they are usually indifferent to address each student (group).
\end{abstract}

\section{INTRODUCTION}

Jiren high school was established as high school in 1988. The school had 4,106 total numbers of students who were learning in the academic year $2004 / 05$. Of this, 1,867 of them were female. As the principal of the school explained, the highest and the lowest number of students in a class was 95 and 84 respectively. Meanwhile, the total number of teachers (as to the record of 2004/05) was 60 , and of this, 9 of them were female. For example, English department has been working with only 9 teachers with whom the researcher dealt at their classroom though students were being taught through satellite TV.

\footnotetext{
* English Dept. Educ. Faculty JU, Jimma, Ethiopia

**English Dept. Educ. Faulty V/Dean JU, Jimma, Ethiopia
} 
Hence the researcher investigated the situation of " classroom interaction" at this high school seeing its relevance for foreign language learning (English, for this matter) from the point of view of experience and different writers initiation.

Larsen-freeman (2000:176) seriously indicated that there is no single approach or method that is advisable for teachers to be rigid to, as learning style is different from student to student. So, she added, elements from different methods and approaches shall be taken and practiced. For language classroom, however, students' interaction is highly considered because it is when they practice, produce or use the language items in focus being either in-group or in pair that they can be good at the language they are learning. Hence, this classroom interaction should be focused on fluency based on communication with some kind of purpose. (Freeman, 2000:179).

Richards and Rodgers (1991:65) pointed out that Communicative Approach aims at communicative competence and enhances procedures and techniques to teach the four-macro skills in integration accepting the interdependency of language and communication. This idea is also supported with Johnson and Marrow (1981:108-114). They underlined that in foreign language classes where Communicative Language Teaching is emphasized, the four skills are not taught in isolation. This is more of due to one language skill is usually dependent upon the other. Thus those skills are integrated and interwoven.

Meanwhile, as the people who have passed through the old curriculum of Ethiopian high schools may not forget it, students sit straight with arms on their chest for lesson after lesson when the teacher teaches. This was highly observable in English classes. Nevertheless, as Marew Zewdie (2000:13-14) states in his book entitled "Secondary Teacher Education in Ethiopia", the current Ethiopian textbooks (the new curriculum) are prepared in such a way that they let students learn more of by themselves being directed and assisted by their teachers. The important question is, however, how much what is said is being done in the schools in general and at the selected grade in particular? 
Finally, the study focused on grade 10, regardless of grade 9 due to the following points: basically, grade 10 students (on the demand of the new curriculum) prepare themselves for the national examination. So, it is critical time for them to take care of their language ability (academic performance). In addition, grade 10 students are more experienced the language than grade 9 students, so that much confusion with the language is not expected from them. Generally, grade 10 classes were in focus so as to check whether there was classroom interaction in line with Communicative Language Teaching or not.

\section{Statement of the Problem:}

The cause of this study is the researcher's personal experience that he had undergone in high school where teachers (English teachers) had been teaching the language through lecturing (talk and chalk), so that students were found to be passive learners. In addition, the researcher has read different books, which recommend more about the importance of Communicative Language. Teacher implementation in English classes. As it could be clear from the topic understudy itself, the investigation was conducted at grade 10 classes to see whether the teachers were practicing the approach through classroom interaction or not. Hence, the researcher worked on this round owing to three more reasons: Obviously, the teaching - learning situation of the country is traditional (taking the high school experience into consideration), and this is the approach which is thought to change the old way of teaching the language because it gives more chance for the students to practice and use the new language they are introduced to.

In addition, as these students are preparing themselves for the national examination to join the preparatory school, the way they are taught the language should get focus so that need to be investigated. Finally, this could be a chance for other researchers to further the study looking at the result of this investigation for the development of English language education in the country.

\section{Significance of the Study:}

As it has been repeatedly indicated above, the research is conducted on grade 10 English classes taking their way to preparatory school and the language's use as medium of instruction in to account. The study is, therefore, supposed to be important for two reasons. 
Firstly, the researcher deals with classroom interaction believing that it will give him an experience, as he himself is to be a teacher on the subject area (English).

The other thing that makes it worth studying is that the result might prepare the stage for other interested researchers to work on. Finally, the researcher takes up the study putting its relevance and implication it has in mind with subsequent objectives.

\section{Objectives:}

The general objective of the study is, therefore, to investigate whether teachers in the selected grade are practicing the approach through classroom interaction or not. It has also the following specific objectives:

* To assess if there is interaction among students (pair or group interaction ).

* To identify if there is student teacher interaction (individual participation in the classroom).

\section{METHODS and MATERIALS}

The researcher used survey method to investigate the problem understudy effectively. These have been briefly explained as follows:

\section{Subject of the Study:}

As the problem may clearly show, the sources of information were the class situation itself (observation while classes were on progress), the students, and the teachers.

Basically, the very source of information for the researcher was classroom observation. This was because practicing classroom interaction is best confirmed at the actual classroom. It was with this belief that the researcher observed 18 different classes with 9 different teachers.

These teachers have been teaching grade 10 students having 2 sections per a teacher. So, the researcher was forced to attain all of the classes putting " speaking skill " as content common to all of the teachers. However, the other contents (vocabulary, reading, grammar, writing and listening) were distributed among them by lot and then observed. The reason why the researcher made " speaking " common to all of the teachers was thinking that it would give ample opportunities for classroom interaction, so teachers weren't to blame the contents for the possible failure. Meanwhile, eighteen students from eighteen classes (sections) were chosen for focus group discussion. To escape 
from gender and educational competence biasness, these students were randomly taken. Then, they were divided in to two groups so as to make it easier for the discussion.

Finally, teachers of the grade were used as the third source of information. Questionnaires revere, there fore, distributed among all teachers (they have been nine in number) because their number was few to treat.

\section{Data Collection:}

After subjects were identified and informed, the prepared instruments were employed for the actual data collection. Fortunately, there wasn't any intense problem seen while data was being collected, so it was properly organized for data analysis to continue

\section{Tools of Data Collection:}

The researcher used three instruments in order to collect reliable data from the subjects. These include observation, questionnaire and focus group discussions.

The researcher took observation as the basic device of data collection because implementation is best witnessed with actual observation. Basically, the researcher and his assistance observed the teaching- learning process being direct observer, not participant observer. This was intentionally done to effectively follow up the teacher's movement, as well as not to let both students and the teacher be conscious of what was being observed in the classroom. Meanwhile, the researcher thought that the presence of observer in the classroom over a little bit long period of time granted and viewed as a part of the natural setting so that the classroom natural behavior wouldn't be much affected.

In addition, as a means to reduce biasness, the researcher made one of his colleagues observe 9 classes and got all observed. Generally speaking, the observers were as ignorant as possible regarding the purpose and hypotheses of the study, and the teachers who have been observed were unaware of what was being observed.

Questionnaires were also distributed among grade ten English teachers. The questionnaires were prepared in both close and open form though open-ended questions were with many items. This was because the researcher wanted to extract sufficient information as it wasn't difficult to analyze responses from only nine individuals 
Focus group discussion was the last instrument used to strengthen the already collected data through observation and questionnaires. Therefore, the researcher made the discussion dividing the selected students (eighteen students) in to two groups. This was because for FGD, only six up to twelve students are recommended. In addition, students were, according to the school schedule, learning in opposite shift. The discussion was, of course, facilitated with the help of tape recorder so as not to as not to miss the idea students were reflecting.

Data Analysis

Once the data were collected, the next step followed was data analysis. This, of course, went through two major steps: data organization, and discussion and interpretation of the already organized data.

The researcher organized the data going through editing and classification. That is, the data was checked for its usefulness and completeness, and then it was classified in to three: observational data, data from teachers, and data of focus group discussion. This was done for analysis convenience.

After the data was effectively organized, discussion and interpretation was facilitated. Descriptive data analysis was dominantly used because most of the questions and the guidelines were open-ended.

\section{RESULTS AND DISCUSSIONS}

\section{Observational Results and \\ Discussions:}

As it has been indicated in the methodology part, 18 classes were observed. In addition, contents of the language, regardless of "speaking", were distributed among 18 grade ten English teachers by lot. Nevertheless, speaking as content for all teachers was treated.

Hence, results and discussions of only three observed classes are, as eight of them are repetitive, gong to be presented one after the other. In fact, two contents observed of a single teacher are to be shown side by side. Mean while, the bold lines in each of almost all boxes show movements of the teacher while the students were left with some discussions, and the dots at the end of these bold lines indicate the teacher's talking to the students.

The students' seating arrangements during observations are also symbolized with a number of small boxes in the big squares. Similarly, the tallies near the 
capital letter "T" which means 'teacher' indicate the time (the number of major points) the teacher alone took to discuss (summarize), particularly near the end of the lesson. Finally, the strokes on the small boxes tell the turns each student got to participate.

These are two classrooms' sketches sketched while the only female teacher from the department was giving help to her students on two different contents (speaking and listening). The total number of a student who presented themselves at the time, when the activities were on progress, was 55 and 42 for the first and the second respectively; and their seating arrangements are sketched above as they were.

For the first case, the topic under discussion was "knower and guesser", that is, an activity done by paired students to develop their speaking skill 
in general. This was a game like lesson played 5 times after the TV teacher invited students to watch the model conversation. Every time when students were let to play the game, the plasma TV teacher requested the classroom teacher to go ahead around the pairs for help and supervision. This was realized by the classroom teacher, as can be seen above. In fact, she took some specific time talking to some 'groups' though there were ignored groups.

For the second case, the activity students did was "writing by listening". It was full of both individual and pair work activities. Primarily, the plasma teacher asked students to work out the meaning of words and to check it with their partners. This time, the classroom teacher went around the students for facilitation and supervision. Students were also made to check spellings of words, indentation, and capitalization one after the other first by themselves and next with their partners. The classroom teacher also facilitated this although there were again ignored groups here, as can be understood in the sketch.

However, in both classroom situations students weren't basically with their own partners (in pairs) though the plasma TV teacher reminded them by giving oneminute time to check it. Of course, the classroom teacher, unlike other observed teachers, tried to group students before class began although it didn't seem successful. Meanwhile, the classroom teacher was busy in trying to group students for 2 minutes at the beginning of class. So, she didn't totally make revision of the previous lesson. Nevertheless, as the tallies in the sketch explain, the teacher made the last 8 minutes time (revision time with out plasma TV) participatory in that students were saying out sentences in how to ask questions for the "guesser" to guess. This was only for the first case (for the first observation class) not for the second case. In the second case, the teacher herself took some 4 minutes to revise what was just discussed. So, the single tally in the first sketch tells that the teacher took a breath to give conclusion to what students tried at the time of revision. Where as, the 5 tallies in the second sketch show the total time the teacher took to revise the already discussed lesson by her with 5 major points. Finally, some of the seats in the first sketch are with strokes showing the number of turns students got to try; but this isn't seen in the second sketch as 
there wasn't individual participation

during the revision time.

These are two different classroom's sketches drawn while another grade ten English teacher was 'teaching' his students. The topics under discussion were "speaking" and "vocabulary". The number of students who attended the lessons was 28 and 16 respectively; In addition, the bold lines in the sketches show the movements of the teacher when students were left to discuss some activities with their partners and the dots with the lines are marks of contact between the teacher and his students.
Mean while, the number of tallies in both classroom sketches reveal the teacher's (the classroom teacher's) speaking frequency over students'; and the strokes on the seats show the frequency students got chance to participate individually. Finally, the second observation was done in the absence of plasma TV so that the whole period was finished with only classroom teacher-students relationship. 
In the first case, "speaking" was treated as content. As the previous, the game as "knower and guesser" was played 5 times aiming to improve students' speaking skill. Even though students' being in pair was very much demanding, as the plasma TV teacher seriously requested, the classroom teacher wasn't observed trying to pair them. However, the teacher was shouting at his students as order for them to try to play the game as shown in the plasma TV. The teacher's shouting wasn't limited to giving order. He was up to using bad words. For example he was heard saying:" I don't know "min litihonu indemitichilu... tesfabis nacho!" (What you will possibly be...you are hopeless!)" This was by no means encouraging, and reveals the teacher's lack of 'self awareness'. The teacher, as can be understood in the sketch, didn't try to go around the students though the plasma TV teacher requested him. In fact, he moved right-left and left right in front of the students, and on the way, he talked to only two groups among frontbenchers. Mean while, there are 4 strokes on two different seats indicating only two students' participation. These students were given chances at the middle and near the end (at the revision time) of the lesson. The tallies close to the big letter "T" (teacher), on the other hand, show that the classroom teacher repeatedly talked as revision. Finally, he went out of class before the total time had gone.

In the second case, the plasma TV wasn't functional so that the classroom teacher was forced to go a head working with his students with out it. So, the topic under discussion was "vocabulary - words related to the passage". However, some thing "strange" was observed in this class. That is, almost the whole period was finished with arguments between the teacher and the students. The teacher, again here, tried to manage the class with "do this ... and "do that..." way - he, it did seem, was running on authoritarian lines. Like in the previous lesson, the teacher spoke very sensitive words to his students: “..."tiviwin eyetemeleketachu admach honachu kerachu... yematirebu!" (watching the plasma TV makes you be passive...worthless!). " Nevertheless, he wasn't totally ignored by his students. There were students who actively participated in attempting meaning to the different words asked; but it was limited to three students. These students participated more than three times, as the strokes in the sketch show. Basically, there wasn't any group or pair 
discussion among the students; but they were individually ordered to copy words from their textbooks, and the teacher was once seen talking to an individual, as the bold line witnesses. Mean while, as the number of tallies tell, the teacher took much time talking on around twelve major points (telling the meaning of words is included here). Generally, most of the students weren't with their own textbooks so that this was the ground for their long time argument.

Here again, the classroom teacher came in late, after the plasma TV had started. He then sat on the chair until the plasma teacher gave order to the students to play the game as they had been shown and a request for the teacher to facilitate students' discussion. As can be seen in the first diagram, the teacher did some sort of movements; however, the 
majority of students were ignored. In addition, there was noting heard from the teacher as revision or summary either at the beginning or end of the lesson. In summary, the teacher was shouting and explaining what the students have to do, but students weren't that much reactive.

In the second section, "grammar: present participle phrases" was discussed as topic of the lesson. Surprisingly, the teacher didn't show any considerable movements though students' discussion, being in pair or ingroup, was demanding. In fact, he said everything either standing or sitting in front of them. Finally, students almost finished their time talking and shouting instead of attain ding the plasma TV lesson. 
The sketches above are drawn while another teacher was giving two different lessons at two different sections. Fortysix for the first and forty-three for the second diagram are the number of students who availed themselves at the time of observations. Students were initially exposed to some game like conversations. Then after, these students themselves played the game around five times as a means to improve their speaking skill. At this time, the classroom teacher went around the students even though he didn't arrange them as ordered by the plasma TV teacher. The teacher, knowingly or unknowingly, ignored the last row by the door in particular and the majority students in general. Lastly, the classroom teacher summarized the lesson by nominating students to give him example statements that the knower and the guesser could say; however, their participation was almost negligible. In the second case, the teacher was facilitating another class holding "passage reading: comprehension" as lesson topic. Firstly, the plasma TV teacher said something about the passage as a revision, and then reminded the students to check if they were with partner. After she had revised what the passage about, she passed to comprehension questions. There were six questions asked by the plasma teacher, and all were left for the students to discuss with their own partners and try. Therefore, the classroom teachers moved around the students for only five questions. As the previous lesson, there were students who were given no attention from their teacher. Unlike the previous section, the teacher went out of class with out revising what had been discussed, so that no student was seen participating individually. Generally, most students weren't with their own textbook, so it created a barrier for the class not to go in line with the plasma teacher. 
Twenty-eight and thirty students for the first and the second case respectively attended the lessons during the other observations.

The lesson topic for the first case was "speaking: knower and guesser" First of all, the teacher was so late that he found the plasma TV started. As soon as he entered class, he began to advise his students, and with this the first model conversation passed however, the teacher and his students together observed the second model conversation. After students where exposed for the second conversational game, they were requested to play the game with their own partners. The problem was they weren't at first arranged in pairs-some were two and some others were three. Nevertheless, the students were seen trying to play the game as they were even though the classroom teacher was ignorant of going around them, as shown in the first sketch. Finally, the teacher went out of class as soon as the plasma TV went off.

In the second case, it was "Readingscanning" which was under discussion. So, students were expected to form a group of three or four members and to make sure that they had texts with them. However, they didn't realize these 
requests from the plasma teacher, and even the teacher didn't try to make some arrangements although he came early unlike the previous session. Despite these problems, the plasma TV teacher arranged around seven questions from the text book for the students to discuss and try them all telling their classroom teacher; but the teacher was simply talking to and telling the students to discuss without going around them. At the end of the lesson, the teacher explained four points as a summary and went out before the school bell sounded.

Finally, the students weren't participating during the progress (at the end) of the lessons, so that no stroke was marked on their seats. The bold lines also witness that the teacher didn't move to any of the students to facilitate the groupings.

To sum up, the total time allocated for a session is 40 minutes. Of this, 3 minutes before the start of the plasma TV and 7 minutes near the end of the session (as soon as the transmission is finished) is always left for the classroom teacher either to revise or to summarize the topic under discussion. In addition, as observed, the discussion time given for the students ranges from 45 seconds to 5 minutes.
Results and Discussions of Focus

\section{Group Discussions:}

As explained in the methodology part, the discussion was facilitated with eighteen students being divided in to two groups. The total number of questions forwarded to these students was seven. Therefore, the result of their discussion is going to be as follows:

The introductory question asked was if they like their English classroom. For this, students said that they like it because of two major reasons: first of all, English, as medium of instruction is the base for other subjects. In addition, knowing and using the language is important to communicate with foreigners. However, some of the participants seriously indicated that there are teachers who discourage students by using first y Amharic) language in English classes.

Participants have also given direct response for what classroom interaction is and who should interact in the classroom. They said that it is the students themselves who should interact and then called classroom interaction. It is, so that, very much forgone that students have the awareness of classroom interaction. 
Mean while, they told the researcher that some teachers let them interact and some other don't they are ignorant of it. In addition, most of the teachers don't go around the students, as told by the discussants. They added that these teachers simply tell they move around few clever students so as to help and encourage them. The participants also informed the researcher that most teachers don't pass the discussion to their students at the time when the plasma TV teacher requested them for; they themselves finish the time with their long time speech replacing their students.

Similarly, the majority of discussants confirmed that they don't usually participate in their English classes due to different reasons:

* It seems that some teachers (English teachers) don't have the interest in their profession, so it puts a negative impact on the interest of the students either to participate or to attend their English class with full attention.

* If some students try to practice and use the language in the class, others of their friends are seen (heard) gossiping about their speech so that it disturbs them.

* Most students are ignorant of participating in the class because most teachers are very much sensitive to clever students they usually ask and have answers from only academically better students.

In spite of the above factors (reasons), there were, however, students who gave positive response as to classroom participation.

Finally, participants mentioned some advantages (but no disadvantages) of interacting in the classroom:

* As the language is the base for other subjects, classroom interaction helps to improve it.

* If one has good command of the language, he will then be encouraged to be good at other subjects. This is, of course, facilitated with classroom in interaction.

* Last but not least, there is always share of ideas.

\section{Results and Discussions from}

\section{Questionnaires:}

Questionnaires were distributed among nine English teachers. Each questionnaire holds five questions that are directly related to the topic under 
investigation. The first point for warded

for all teachers was the thing that comes

to their mind when they think of classroom interaction. For this, almost all teachers touched the issue of groupings, students' participation, and generally Communicative Approach.

However, only two teachers wrote as noise comes to their mind. Therefore, it seems that seven of them have the concept of classroom interaction in particular and communicative approach in general; but two of them understand classroom interaction negatively.

For the relationship between classroom interaction and communicative language Teaching, all agreed that classroom interaction is part and parcel of communicative language teaching.

Thirdly, they were provided with question that asks whether they think classroom interaction helps foreign language learners (their students) or not. All of them tried to give explanations why they are positive to the idea raised above; but generally they think students will have good command of the language if they involved themselves in classroom interaction. So, it witnesses that these teachers admit the importance of classroom interaction.

Meanwhile, two teachers responded that they practice classroom interaction whenever necessary. In fact, they usually facilitate it with instruction to make their students form groups and pairs. Other respondents said that they practice it every time at every class; but they said nothing regarding the way they practice it.

Lastly, the teachers were given a chance to say something about their school or classroom environment (if it is favorable to practice classroom interaction). Eight of the respondents responded that the classroom situation isn't favorable: the class size in a section is large and the way the plasma TV teacher teaches isn't convenient.

\section{CONCLUSIONS}

It has been repeatedly explained that the study made its focus on what is going on at the actual classrooms. Hence, it has now come out with the following prominent findings:

Almost all teachers have the awareness of classroom interaction and its importance for foreign language learners; but they don't have the habit of organizing their students either in group or in pair before the start of the lesson. Some teachers, of course, go around the 'groupings' at the time of discussion although they are usually unable (indifferent) to address each student (pair or group). 
On the other hand, most students aren't active participant in their classrooms in general and during pair or group discussions in particular. In fact, the number of students who participate individually is almost negligible. This is mainly because teachers themselves discourage students losing an interest in what they are doing-they are careless. In addition, students know that the teacher may come around to talk to only the clever one.

Last but not least, most students are very ignorant of bringing their own English textbooks. This actually creates a problem for appropriate classroom management.

Generally, grade ten English teachers in the school don't basically arrange their students, so the discussion time lapse given by the plasma TV teacher isn't (can't be) appropriately used among the students. Most teachers don't also go efficiently and interestingly around the students who disorderly sit on for discussion. Therefore, teachers of the grade aren't practicing classroom interaction as suggested and recommended by different scholars of the study.

\section{RECOMMENDATIONS}

So far, the researcher has listed out major findings of the study. These findings seem to be very important for the teachers to take in to account for their own professional development. Therefore, the researcher, as a professional, would like to suggest course of actions as solutions for the major problems identified.

In a general sense, almost all teachers are negligent as far as students' seating arrangement is concerned. However, it is more difficult (time taking) for the teachers to efficiently proceed group or pair discussion at the class where satellite TV is on progress. Therefore, teachers shall organize the students before class begins by using different techniques. For example, students might be conditioned to group or pair formation if they are mostly exposed to different (language) games that usually demand them to form pairs or groups. Games may also help students to develop an interest in the subject matter so that they may participate in the actual classroom activities. In addition, giving prize (if possible) may increase students' interest to participate.

Similarly, teachers' personality or their commitment to the profession has a 
great impact on the interest of the students; it either diminishes or arises their interest. Therefore, teachers shall be very sensitive to what they do both inside and outside classroom. Finally, if the teacher himself respects the profession and draws the attention of his students to make fun of the language (the class), students may listen to what the teacher talks or orders; they may be obedient to bring the necessary materials including their textbook to the class.

Generally, because most teachers are aware of what classroom interaction is and its strong relationship to "Communicative Approach", they should practically show the theory they know. In fact, teachers should try to visit each member of the group (to know they really involve in it) and go around each pair or group as well.

\section{ACKNOWLEDGEMENTS}

My gratitude goes up to all those who stood on my side during the progress of the whole study. My heartfelt enthusiasm particularly extends to

Mr. Yemanebirhan Kelemwork for his invaluable and restless support both in terms of consultation and materials provision. My special thankfulness is also due for a score of staff members of Jimma University all of whose names get too difficult to mention. I am highly particularly indebted to Mrs. Selam Mekbib and Mrs. Tizita Godu for typing $\&$ printing all the manuscript.

\section{REFERENCE}

1. Cable Industry's Education

Foundation. "Evidence that technology

support learning" Learning with

Technology. http://www.ciconline. Com /broadband/learningwithtechnology/defa ult.htm (5/27/2005).

2. Johnson, K. and Moorrow, K. 1981.

\section{Communication in the classroom:}

Applications and Methods for a Communicative Approach. Hong Kong: Long man Group (FE) Ltd.

3. Larsen - $\quad$ Freeman, D.2000.Techniques and principles in

Language Teaching. Oxford: OUP.

4. Luft, J.1970.Group Processes: An Introduction to Group Dynamics. California:

Mayfield publishing Company.

5. Ministry of Education: Teachers Guide, Education Media Agency.2004.

6. Peter, H., Lindsay, and Norman. "Television" Human Information processing.

http://www.interlingua.

Org/glossary/GLS-Gloss ary.htm (9/18/2004) 
7. Richards, J. \& Theodres Rodgers. 1991. Approaches and Methods in

Language Teaching. Cambridge: CUP

8. Rivers, M.W.1987. Interactive

Language Teaching. Cambridge: CUP.

9. Zewdie, M. and Bridges, D.2000.

Secondary Teacher Education in Ethiopia.

Ethiopia: Addis Ababa University printing office. 